\title{
The effects of marijuana smoking on lung function in older people
}

\author{
Wan C. Tan ${ }^{1}$, Jean Bourbeau (10) ${ }^{2}$, Shawn D. Aaron ${ }^{3}$, James C. Hogg ${ }^{1}$, \\ Francois Maltais ${ }^{4}$, Paul Hernandez ${ }^{5}$, Darcy D. Marciniuk ${ }^{6}$, Kenneth R. Chapman (107, \\ Teresa $\mathrm{To}^{8}$, J. Mark FitzGerald ${ }^{9}$, Brandie L. Walker ${ }^{10}$, Jeremy Road ${ }^{9}$, Liyun Zheng ${ }^{1}$, \\ Guohai Zhou ${ }^{1}$, Trevor Yau ${ }^{1}$, Andrea Benedetti ${ }^{2}$, Denis O'Donnell (1) ${ }^{11}$ and \\ Don D. $\operatorname{Sin}^{1}$, on behalf of the CanCOLD Collaborative Research Group ${ }^{12}$
}

\begin{abstract}
Affiliations: ${ }^{1}$ The University of British Columbia, Center for Heart Lung Innovation, St Pauls's Hospital, Vancouver, BC, Canada. ${ }^{2}$ Research Institute McGill University Health Center, McGill University, Montreal, QC, Canada. ${ }^{3}$ The Ottawa Hospital Research Institute, University of Ottawa, Ottawa, ON, Canada. ${ }^{4}$ Institut Universitaire de cardiologie et de pneumologie de Québec, Université Laval, Quebec City, QC, Canada. ${ }^{5}$ Dept of Medicine, Dalhousie University, Halifax, NS, Canada. ${ }^{6}$ Respiratory Research Centre, University of Saskatchewan, Saskatoon, SK, Canada. ${ }^{7}$ Toronto General Hospital Research Institute, University of Toronto, Toronto, ON, Canada. ${ }^{8}$ Dalla Lana School of Public Health, University of Toronto, Toronto, ON, Canada. ${ }^{9}$ University of British Columbia, Dept of Medicine, Vancouver General Hospital, Vancouver, BC, Canada. ${ }^{10}$ Dept of Medicine, University of Calgary, Calgary, AB, Canada. ${ }^{11}$ Division of Respiratory and Critical Care Medicine, Queen's University, Kingston, ON, Canada. ${ }^{12} \mathrm{~A}$ list of members of the CanCOLD Collaborative Research Group can be found in the acknowledgements section.
\end{abstract}

Correspondence: Wan C. Tan, University of British Columbia, Centre for Heart Lung Innovation, St Paul's Hospital, Rm166, 1081 Burrard Street, Vancouver, BC, V6Z 1Y6, Canada. E-mail: wan.tanahli.ubc.ca

@ERSpublications

Prolonged heavy marijuana smoking increases the risk of COPD and accelerates FEV $_{1}$ decline in concomitant tobacco cigarette smokers beyond the effects of tobacco alone http://bit.ly/2li2lEu

Cite this article as: Tan WC, Bourbeau J, Aaron SD, et al. The effects of marijuana smoking on lung function in older people. Eur Respir J 2019; 54: 1900826 [https://doi.org/10.1183/13993003.00826-2019].

\section{ABSTRACT}

Background: Previous studies have associated marijuana exposure with increased respiratory symptoms and chronic bronchitis among long-term cannabis smokers. The long-term effects of smoked marijuana on lung function remain unclear.

Methods: We determined the association of marijuana smoking with the risk of spirometrically defined chronic obstructive pulmonary disease (COPD) (post-bronchodilator forced expiratory volume in $1 \mathrm{~s}$ $\left(\mathrm{FEV}_{1}\right)$ /forced vital capacity ratio $\left.<0.7\right)$ in 5291 population-based individuals and the rate of decline in $\mathrm{FEV}_{1}$ in a subset of 1285 males and females, aged $\geqslant 40$ years, who self-reported use (or non-use) of marijuana and tobacco cigarettes and performed spirometry before and after inhaled bronchodilator on multiple occasions. Analysis for the decline in $\mathrm{FEV}_{1}$ was performed using random mixed effects regression models adjusted for age, sex and body mass index. Heavy tobacco smoking and marijunana smoking was defined as $>20$ pack-years and $>20$ joint-years, respectively.

Results: $\sim 20 \%$ of participants had been or were current marijuana smokers with most having smoked tobacco cigarettes in addition (83\%). Among heavy marijuana users, the risk of COPD was significantly increased (adjusted OR 2.45, 95\% CI 1.55-3.88). Compared to never-smokers of marijuana and tobacco, heavy marijuana smokers and heavy tobacco smokers experienced a faster decline in $\mathrm{FEV}_{1}$ by $29.5 \mathrm{~mL} \cdot \mathrm{year}^{-1}$ $(\mathrm{p}=0.0007)$ and $21.1 \mathrm{~mL} \cdot \mathrm{year}^{-1}(\mathrm{p}<0.0001)$, respectively. Those who smoked both substances experienced a decline of $32.31 \mathrm{~mL} \cdot \mathrm{year}^{-1}(\mathrm{p}<0.0001)$.

Interpretation: Heavy marijuana smoking increases the risk of COPD and accelerates $\mathrm{FEV}_{1}$ decline in concomitant tobacco smokers beyond that observed with tobacco alone. 


\section{Introduction}

Marijuana is the second most common substance smoked in the world after tobacco [1], and the most common illicit drug used by the older population in the United States [2]. Concerns regarding the respiratory effects of marijuana smoking are based on the fact that marijuana and tobacco are qualitatively similar, with the exception of the active ingredients, $\delta$-9-tetrahydro-cannabinol and other cannabinoids in marijuana and nicotine in tobacco.

The harmful respiratory effects of tobacco are well characterised [3], but comparable data for marijuana are not available [4]. Most epidemiological studies support an increased association between marijuana smoking and chronic respiratory symptoms [5], but the effects on lung function remain unclear. Some cross-sectional studies [6-9] have demonstrated that marijuana smoking was associated with a decrease in forced expiratory volume in $1 \mathrm{~s}\left(\mathrm{FEV}_{1}\right) /$ forced vital capacity $(\mathrm{FVC})$ ratio and isolated impaired large airway function as indicated by specific airway conductance, while other studies have failed to find such an association $[10,11]$, with three reporting an increase in FVC $[9,12,13]$. To date, longitudinal studies $[12,14-17]$ have also shown conflicting results: no accelerated decline in $\mathrm{FEV}_{1}$ in a convenience sample of heavy smokers [16]; a suggestion of gas trapping in a population cohort [12]; a possible reduction in $\mathrm{FEV}_{1}$ or $\mathrm{FEV}_{1} / \mathrm{FVC}$ ratio associated with high levels of marijuana smoking $[14,15]$; and a paradoxical increase in $\mathrm{FEV}_{1}$ in current marijuana smokers in a study of four consecutive surveys of non-tobacco smokers assumed to be marijuana smokers [17].

In this study, we analysed cross-sectional [18] and longitudinal data from the Canadian Cohort Obstructive Lung Disease (CanCOLD) study consisting of males and females, aged 40-85 years [19] to investigate the association of marijuana smoking with the risk of chronic obstructive pulmonary disease (COPD) and the decline in lung function over time.

\section{Methods}

\section{Study design and participants}

Written informed consent was obtained from all participants in this multicentre study (nine sites in six Canadian provinces), which was approved by the institutional review boards of each site. Briefly, the study comprised two phases: an initial cross-sectional component called the Canadian Obstructive Lung Disease (COLD) study, which was a population-based prevalence study that recruited a random sample of 5291 participants aged $\geqslant 40$ years from nine Canadian urban sites $[18,20]$; and a subsequent longitudinal phase (CanCOLD study), which comprised a subset of 1285 participants who were assessed every 18 months [19]. These participants were derived from the COLD cross-sectional cohort and consisted of individuals with COPD (defined as post-bronchodilator $\mathrm{FEV}_{1} / \mathrm{FVC}$ ratio $<0.7$ ) and approximately equal number of ageand sex-matched never-smokers and ever-smokers who demonstrated normal lung function. Full details of the longitudinal phase of the study have been published elsewhere [19, 21, 22]. Data from both the cross-sectional and longitudinal phases of the study were collected between August 2005 and January 2017 , with $80 \%$ retention rate of the longitudinal cohort at the end of January 2017 . The study was registered with ClinicalTrials.gov identifier NCT00920348.

\section{Procedures and definitions}

At each visit, participants answered structured questionnaires on respiratory symptoms, self-reported doctor diagnosis of respiratory diseases, and smoking of tobacco and marijuana (the marijuana smoking questionnaire can be found in the supplementary material). Study definitions were as follows. Tobacco smokers if participants had smoked $\geqslant 365$ cigarettes in a lifetime [23] and marijuana smokers if they had smoked $\geqslant 50$ joints in a lifetime [10]. Cumulative marijuana exposure was quantified as "joint-years" (number of joints smoked per day multiplied by years) [7, 14]. Cumulative tobacco exposure was quantified as "pack-years" (number of packs of cigarettes (20 per pack) smoked per day multiplied by years) [14]. Chronic cough, chronic phlegm, wheeze and dyspnoea were defined as in previous publications $[10,18,23,24]$.

Smoking patterns were defined as marijuana-only, tobacco-only, both marijuana and tobacco (MT) and never-smokers of both marijuana and tobacco. Current smokers were defined as those smoking at the time of the interview and former smokers as those who had quit smoking at the time of the interview. Based on the findings from a previous longitudinal study [14], the associations between smoking exposures and lung

This article has supplementary material available from erj.ersjournals.com

Received: 25 April 2019 | Accepted after revision: 6 Sept 2019

The study is registered at ClinicalTrials.gov with identifier number NCT00920348. 
function were stratified based on levels of exposure (mild $1-5$, moderate $>5-20$, heavy $>20$ ) in joint-years or pack-years marijuana or tobacco use, respectively.

All participants performed spirometry testing using an EasyOne spirometer (ndd Medical Technologies, Andover, MA, USA) before and $15 \mathrm{~min}$ after inhalation of $200 \mu \mathrm{g}$ albuterol [25] according to the American Thoracic Society guidelines [26].

\section{Statistical analyses}

The cross-sectional data from 5291 participants were utilised to evaluate the relationship of marijuana smoking or tobacco smoking with the risk of COPD (post-bronchodilator $\mathrm{FEV}_{1} / \mathrm{FVC}<0.7$ ) [27] using multivariable logistic regression analyses. A separate model was constructed for each of the subgroups of marijuana smokers and tobacco smokers, controlling for pack-years or joint-years, respectively, and for age, sex and body mass index (BMI). The adjusted odds ratios (aORs) and 95\% confidence intervals were computed for each level of marijuana or tobacco exposure. The reference category for all analyses was never-smokers. Linear relationships across the smoking categories were assessed using a Cochran-Armitage test of trend.

A linear random mixed effects model was used $[16,28]$ on the longitudinal data to estimate the declines in $\mathrm{FEV}_{1}$ over time (details in supplementary material). Separate models were constructed for marijuana smoking (controlling for pack-years) and tobacco smoking (controlling for joint-years). The predictor variable was marijuana or tobacco exposure defined at baseline by joint-year or pack-year cut-offs; the outcome variable was decline in $\mathrm{FEV}_{1}$ over time $\left(\mathrm{mL} \cdot \mathrm{year}^{-1}\right)$, controlling for potential confounding variables which included BMI, follow-up time, sex, baseline $\mathrm{FEV}_{1}$ and baseline age (more details in supplementary material). Current and former smoking status was similarly examined in heavy marijuana smokers (>20 joint-years) and heavy tobacco smokers ( $>20$ pack-years). In a sensitivity analysis, we directly compared the change over time across the different strata of tobacco smoking exposure, segregating the data on whether or not there was concurrent marijuana smoking.

The assumptions of the linear mixed effect models were checked to ensure the validity of the model (details in supplementary material). The Akaike information criterion [29] was used for testing the goodness of fit and model selection for the regression methods. All statistical analyses were performed using SAS 9.4 software (SAS Institute, Cary, NC, USA).

\section{Results}

\section{Patient characteristics}

The cross-sectional data (COLD) included 5291 participants with information on marijuana and tobacco smoking and the longitudinal data (CanCOLD) included 1285 participants (details for each visit are shown in the flow diagram in supplementary figure E1 and table E1). The baseline characteristics of the participants in COLD and CanCOLD stratified by smoking habits are summarised as univariate descriptive statistics in tables 1 and 2, respectively. Compared with the COLD cohort, the CanCOLD cohort contained older individuals (median age 65 years versus 59 years), more males and more tobacco smokers (supplementary table E1). The median duration of follow-up in the CanCOLD cohort was 5.9 (interquartile range (IQR) 4.9-6.7) years and range 2.5-10.5 years.

The frequencies of tobacco and marijuana smoking were similar in the COLD and CanCOLD cohorts: $36 \%$ were tobacco smokers, $3 \%$ were marijuana smokers and $17 \%$ were smokers of both marijuana and tobacco in COLD, versus $44 \%$ tobacco smokers, $3 \%$ marijuana smokers and $16 \%$ smokers of both marijuana and tobacco in CanCOLD. Tobacco-only smokers comprised the majority (69\% COLD, 73\% CanCOLD) of all tobacco smokers, while marijuana-only smokers comprised a minority of all marijuana smokers (17\% COLD, $14 \%$ CanCOLD) and $83 \%$ and $86 \%$ of all marijuana smokers also smoked tobacco in the two cohorts, respectively.

In both cohorts, marijuana smokers were younger, included more males, and were better educated than tobacco smokers. The ages of onset of smoking for marijuana and tobacco smokers were 17-19 years and 15-18 years, respectively. The median durations of marijuana exposure at baseline were the same in the two cohorts $(\sim 11$ years) while that for tobacco exposure was 26 years in COLD and 33 years in CanCOLD. The cumulative marijuana exposure at baseline in smokers of both marijuana and tobacco was more than twice that in marijuana smokers: mean 17.02 joint-years versus 7.23 joint-years in COLD and 16.68 joint-years versus 5.45 joint-years in CanCOLD. Current marijuana smokers in CanCOLD smoked more than twice as much as former smokers: mean 25.72 joint-years versus 10.40 joint-years.

\section{Cumulative marijuana smoking and FEV $/$ FVC ratio}

Cumulative marijuana exposure of $>20$ joint-years controlled for tobacco pack-year exposure was associated with the presence of COPD (post-bronchodilator $\mathrm{FEV}_{1} / \mathrm{FVC}<0.7$ ) (figure $1 \mathrm{a}$, supplementary 
TABLE 1 Baseline demographics and general characteristics of the participants in the initial cross-sectional (Canadian Obstructive Lung Disease (COLD)) cohort stratified into four smoking subgroups

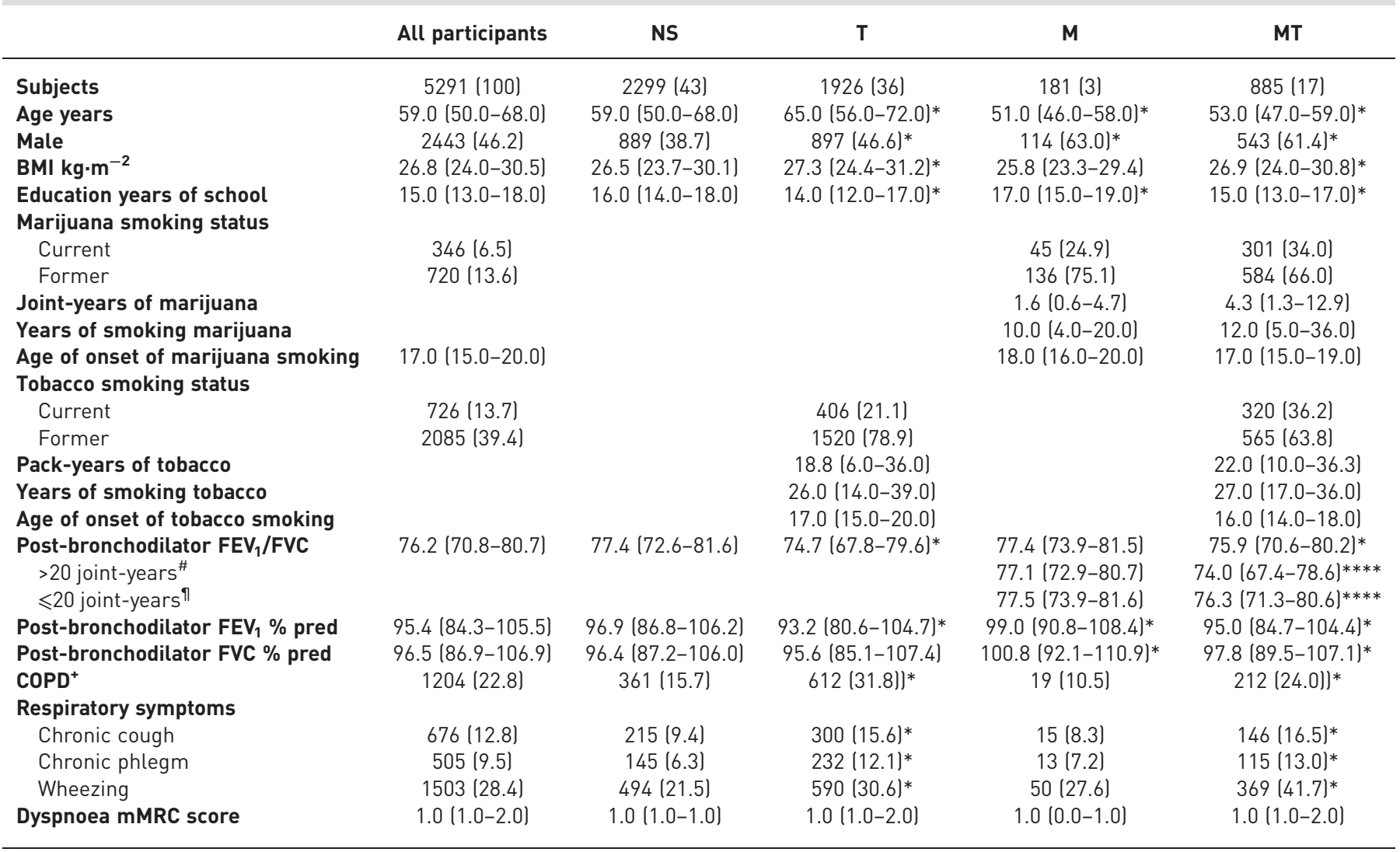

Data are presented as $\mathrm{n}(\%)$ or median (interquartile range). NS: never-smokers of either tobacco or marijuana; T: tobacco smoking only; M: marijuana smoking only; MT: smokers of both marijuana and tobacco; BMI: body mass index; joint-years: number of joints per dayxtotal duration of smoking in years; pack-years: number of packs (20 cigarettes per pack) per dayxtotal duration of smoking in years; $F E V_{1}$ : forced expiratory volume in $1 \mathrm{~s}$; FVC: forced vital capacity; COPD: chronic obstructive pulmonary disease; mMRC: modified Medical Research Council. ${ }^{\#}: \mathrm{n}=17(\mathrm{M}), \mathrm{n}=168(\mathrm{MT}) ;{ }^{\mathrm{T}}: \mathrm{n}=164(\mathrm{M}), \mathrm{n}=717(\mathrm{MT}) ;{ }^{+}:$the proportion of COPD in any marijuana smoker is $21.7 \%$, and the proportion of COPD in any tobacco smoker is $29.3 \%$. $^{*}$ : significantly different to NS as reference $(p<0.05)$; ${ }^{* * * *}$ : significantly different to each other ( $\left.p<0.0001\right)$.

table E2). Lower cut-offs of joint-years were not significantly associated, but a trend was found with increasing cumulative marijuana exposure: aOR (95\% CI) $1.39(0.96-2.02)$ for $1-5$ joint-years, $1.28(0.84-$ $1.95)$ for $>5-20$ joint-years and 2.45 (1.55-3.90) for $>20$ joint-years, with a significant Cochran-Armitage test of trend for increasing marijuana smoked $(\mathrm{p}<0.0001)$. The results for cumulative tobacco exposure showed that cumulative tobacco exposure of $>5$ pack-years was associated with COPD (figure $1 \mathrm{~b}$, supplementary table E3). There was a significant interaction between marijuana and tobacco smoking on $\mathrm{FEV}_{1} / \mathrm{FVC}$ ratio $(\mathrm{p}=0.042)$.

Cumulative marijuana smoking and the longitudinal decline in FEV

The results of four separate random mixed-effect models comparing the decline of $\mathrm{FEV}_{1}$ in marijuana smokers (controlled for tobacco exposure) and tobacco smokers (controlled for marijuana exposure) versus never-smokers are summarised as $\beta$-coefficients (95\% CI and absolute change) in table 3.

For all marijuana smokers with $>20$ joint-years exposure, the rate of decline in $\mathrm{FEV}_{1}$ (controlled for tobacco exposure and independent of the presence of COPD) was significantly greater than in never-smokers by, on average $29.6 \mathrm{~mL} \cdot$ year $^{-1}$ (absolute decline $40.5 \mathrm{~mL} \cdot$ year $^{-1}$ ). For all tobacco smokers with $>20$ pack-years of exposure, the decline in $\mathrm{FEV}_{1}$ (controlled for marijuana exposure) was significantly greater than that in never-smokers by $21.1 \mathrm{~mL} \cdot \mathrm{year}^{-1}$ (absolute decline $32.5 \mathrm{~mL} \cdot \mathrm{year}^{-1}$ ) (table 3, figure 2a,b). The declines in $\mathrm{FEV}_{1}$ for smokers with lower exposures of marijuana or tobacco were not signficant compared with never-smokers. There was a significant interaction between marijuana and tobacco smoking $(\mathrm{p}<0.0001)$. FVC declined with a pattern similar to $\mathrm{FEV}_{1}$ (supplementary table E4). 
TABLE 2 Baseline characteristics of the participants in the longitudinal Canadian Cohort Obstructive Lung Disease (CanCOLD) cohort stratified into four smoking subgroups

\begin{tabular}{|c|c|c|c|c|c|}
\hline & All participants & NS & $\mathbf{T}$ & M & MT \\
\hline Subjects & 1285 & 482 (37) & $561(44)$ & $33(3)$ & $209(16)$ \\
\hline Age years & $65.0(59.0-72.0)$ & $66.0(59.0-72.0)$ & $68.0(63.0-74.0)^{*}$ & $53.0(51.0-60.0) *$ & $58.0(52.0-63.0) *$ \\
\hline BMI $\mathrm{kg} \cdot \mathrm{m}^{-2}$ & $26.8(24.0-30.4)$ & $26.6(23.9-29.7)$ & $27.1(24.4-30.9)^{*}$ & $24.7(22.4-28.1)$ & $26.5(23.5-29.9)$ \\
\hline Education years of school & $16.0(13.0-18.0)$ & $16.0(14.0-18.0)$ & $15.0(12.0-17.0)^{*}$ & $17.0(15.0-18.0)$ & $16.0(14.0-18.0)$ \\
\hline Follow-up time years & $5.9(4.9-6.7)$ & $6.1(5.4-7.0)$ & $5.7(4.1-6.3)^{*}$ & $6.6(6.0-8.1)$ & $5.4(3.2-7.3)^{*}$ \\
\hline Former & $151(11.8)$ & & & $26(78.8)$ & $125(59.8)$ \\
\hline Joint-years of marijuana & & & & $1.7(0.7-5.4)$ & $5.3(1.4-17.1)$ \\
\hline Years of smoking marijuana & & & & $10.0(4.0-20.0)$ & $12.0(5.0-34.0)$ \\
\hline $\begin{array}{l}\text { Age of onset of marijuana } \\
\text { Tobacco smoking status }\end{array}$ & $18.5(16.0-21.0)$ & & & $18.0(16.0-20.0)$ & $19.0(16.0-21.0)$ \\
\hline Current & 222 (17.3) & & 134 (23.9) & & $88(42.11)$ \\
\hline Post-bronchodilator $\mathrm{FEV}_{1} / \mathrm{FVC}$ & $69.4(64.3-76.7)$ & $72.4(66.5-78.3)$ & $68.4(62.5-75.4)^{*}$ & $74.7(67.3-79.7)$ & $68.6(63.1-75.5)^{*}$ \\
\hline$>20$ joint-years ${ }^{\#}$ & & & & $74.7(65.8-83.6)$ & $63.8(60.1-70.0)^{* * *}$ \\
\hline$\leqslant 20$ joint-years ${ }^{\Uparrow}$ & & & & $74.8(67.3-79.7)$ & $69.6(64.8-76.5)^{* * *}$ \\
\hline Post-bronchodilator FEV $_{1} \%$ pred & $91.4(77.6-103.5)$ & $96.0(83.0-106.6)$ & $87.0(73.6-100.0)^{*}$ & 97.5 (90.1-105.5) & $88.5(75.7-101.8)^{*}$ \\
\hline Post-bronchodilator FVC \% pred & 97.5 (86.9-109.5) & $100.0(90.0-110.3)$ & $94.7(83.7-108.1)^{*}$ & $105.6(92.2-114.0)$ & $97.9(88.6-109.4)$ \\
\hline $\mathrm{COPD}^{+}$ & $659(54.1)$ & $214(44.4)$ & $349(62.2)^{*}$ & $11(33.3)$ & $121(57.9)^{*}$ \\
\hline \multicolumn{6}{|l|}{ Respiratory symptoms } \\
\hline Chronic cough & $199(15.5)$ & $53(11.0)$ & $102(18.2)^{*}$ & $3(9.1)$ & $41(19.6)^{*}$ \\
\hline Chronic phlegm & $160(12.5)$ & $31(6.4)$ & $83(14.8)^{*}$ & $4(12.1)$ & $42(20.1)^{*}$ \\
\hline Wheezing & $415(32.3)$ & $110(22.8)$ & $196(34.9)^{*}$ & 9 (27.3) & 100 (47.9)* \\
\hline Dyspnoea mMRC score & $1.0(1.0-2.0)$ & $1.0(1.0-1.0)$ & $1.0(1.0-2.0)$ & $1.0(1.0-1.0)$ & $1.0(1.0-2.0)$ \\
\hline
\end{tabular}

Data are presented as $n$, median (interquartile range) or $n$ (\%). NS: never-smokers of either tobacco or marijuana; T: tobacco smoking only; M: marijuana smoking only; MT: smokers of both marijuana and tobacco; BMI: body mass index; follow-up time: baseline to last visit for each individual; joint-years: number of joints per dayxtotal duration of smoking in years; pack-years: number of packs (20 cigarettes per pack) per dayxtotal duration of smoking in years; $\mathrm{FEV}_{1}$ : forced expiratory volume in $1 \mathrm{~s}$; FVC: forced vital capacity; COPD: chronic obstructive pulmonary disease; mMRC: modified Medical Research Council. ${ }^{\#}: n=3(M), n=48(M T) ;{ }^{9}: n=30(M), n=161(M T) ;{ }^{*}$ : the proportion of COPD in any marijuana smoker is $54.5 \%$, and the proportion of COPD in any tobacco smoker is $61.0 \%{ }^{*}$ : significantly different to NT as reference (p<0.05); ${ }^{* * *}$ : significantly different to each other $(p=0.001)$.

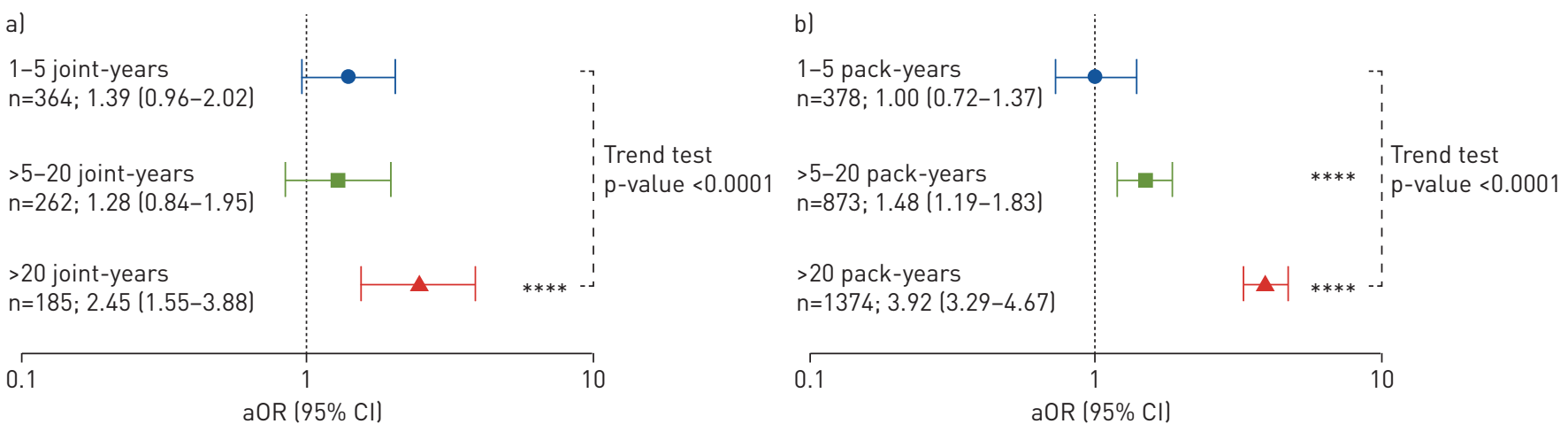

FIGURE 1 Adjusted odds ratios (aORs) with 95\% confidence interval for association of a) cumulative marijuana exposures by three joint-years cut-offs $(1-5,>5-20,>20)$, b) cumulative tobacco exposures by three pack-years cut-offs $(1-5,>5-20,>20)$, with presence of chronic obstructive pulmonary disease (post-bronchodilator forced expiratory volume in $1 \mathrm{~s} /$ forced vital capacity ratio $<0.7$ ). The aORs and $95 \%$ confidence intervals for the lowest exposure subgroup for marijuana $>0$ and $<1 \quad(n=253)$ and for tobacco $>0$ and $<1 \quad(n=124)$ are not significant and not shown in the figures, but values are in supplementary tables E2 and E3. The aORs were adjusted for a) age, sex, body mass index and pack-years or b) joint-years. A potential trend was evaluated using a Cochran-Armitage test of trend. ${ }^{* * * *}$ : $p<0.0001$. 
TABLE 3 Results from mixed-effects regression models for marijuana smokers and tobacco smokers showing the longitudinal lung function decline ladjusted for pack-years or joint-years and other covariates) shown as rate of change in forced expiratory volume in $1 \mathrm{~s}\left(\mathrm{FEV}_{1}\right)$

Predictor variables
Subjects $\mathbf{n}$

Rate of change in $\mathrm{FEV}_{1} \mathrm{~mL} \cdot \mathrm{year}^{-1}$

Absolute change

\section{Model 1}

Never-smokers (reference)

Marijuana smoking joint-years groups

$>0-1$

$>1-5$

$>5-20$

$>20$

\section{Model 2}

Never-smokers (reference)

Tobacco smoking pack-years groups

$>0-1$

$>1-5$

$>5-20$

$>20$

B-coefficient $(95 \% \mathrm{CI})$

\section{Model 3}

Never-smokers (reference)

Heavy marijuana smoking ( $>20$ joint-years) Current Former

\section{Model 4}

Never-smokers (reference)

Heavy tobacco smoking (>20 pack-years) Current

Former

$\begin{array}{ccc}482 & -10.75 & -10.75 \\ 56 & -7.28(-17.95-3.40) & -18.03 \\ 72 & -16.51(-33.18-0.17) & -27.26 \\ 63 & 2.12(-9.55-13.78) & -8.63 \\ 51 & -29.45(-46.58--12.32)^{*} & -40.20 \\ & & \\ 482 & -11.20 & -11.20 \\ & & -8.98 \\ 59 & 2.22(-15.67-20.10) & -9.98 \\ 65 & 1.22(-9.88-12.32) & -17.98 \\ 207 & -6.78(-15.37-1.80) & -32.33 \\ 439 & -21.13(-27.46--14.81)^{*} & -11.46 \\ & & \\ 482 & -11.46 & -42.37 \\ & & -38.56 \\ 34 & -30.91(-53.56--8.27)^{*} & -9.74 \\ 17 & -27.10(-51.78--2.42)^{*} & -50.06 \\ & & -18.16\end{array}$

The $\beta$-coefficient for each smoking subgroup/category is the mean rate of change of $F E V_{1}$ relative to (compared with) the reference (never-smokers of either tobacco or marijuanal. The absolute rate of decline for the smoking subgroup is therefore $\beta$-coefficient of the subgroup added to the rate of decline of the reference (never-smoker); for example, in model 1, the absolute change for marijuana smokers of $>20$ joint-years is the sum of -29.45 and -10.75 , that is $-40.20 \mathrm{~mL} \cdot y e a r^{-1}$. In model 2 , the absolute change for tobacco smokers of $>20$ pack-years is $-32.33 \mathrm{~mL} \cdot \mathrm{year}^{-1}$, and so on for models 3 and $4 .{ }^{*}$ : significantly different compared with that of never-smokers of either marijuana or tobacco, $p<0.05$.
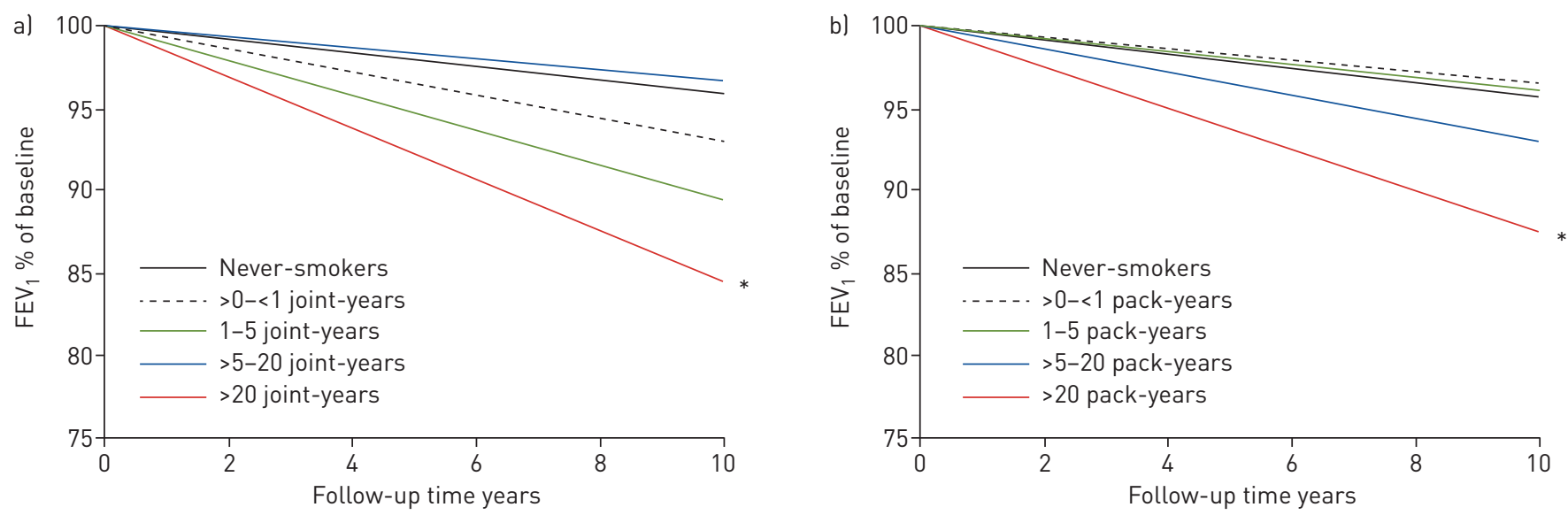

FIGURE 2 Decline in forced expiratory volume in $1 \mathrm{~s}\left(\mathrm{FEV}_{1}\right)$ over time for a) cumulative exposure to marijuana smoke controlled for pack-years; b) cumulative exposure to tobacco smoke, controlled for joint-years. Other covariates controlled for: sex, body mass index, baseline age, baseline $\mathrm{FEV}_{1}$, follow-up time and presence or absence of chronic obstructive pulmonary disease $\left(\mathrm{FEV}_{1} / \mathrm{forced}\right.$ vital capacity $\left.<0.7\right)$. The decline in $\mathrm{FEV} \mathrm{V}_{1}$ is expressed as percentage of baseline $\mathrm{FEV}_{1}$ over time, projected using the $\beta$-coefficients from the mixed-effect models (data in table 3 ) and right-truncated at 10 years of follow-up. *: significantly different from never-smokers. 
TABLE 4 Results from mixed-effects regression models showing the change in forced expiratory volume in $1 \mathrm{~s}\left(\mathrm{FEV}_{1}\right)$ over time between the different strata of tobacco smoking exposures, segregated by whether or not there was concurrent marijuana smoking

Tobacco-smoking groups by pack-years

Rate of change in $\mathrm{FEV}_{1} \mathrm{~mL} \cdot \mathrm{year}^{-1}$

B-coefficient $(95 \% \mathrm{CI}) \quad$ p-value

\section{$0-1(T)$}

$>1-5(\mathrm{~T})$

$>1-5$ (MT)

$>5-20(\mathrm{~T})$

$>5-20$ (MT)

$>20(\mathrm{~T})$

$>20$ (MT)

$\begin{array}{cc}\text { Reference } & \\ 12.59(-2.22-27.40) & 0.0955 \\ -4.74(-16.08-6.60) & 0.412 \\ 7.05(-4.52-18.61) & 0.232 \\ -2.392(-12.51-7.72) & 0.6428 \\ -23.66^{\#}(-34.52--12.79) & <0.0001 \\ -32.31^{\#}(-42.02--22.6) & <0.0001\end{array}$

T: tobacco smoking only; MT: smokers of both marijuana and tobacco. " : significantly different from each other; $p=0.019$ (F-test).

In a sensitivity analysis, the trajectories of the subgroups of different strata of tobacco smoking exposure segregated by whether or not there was concurrent marijuana smoking showed that the presence of marijuana significantly increased the magnitude of change for tobacco exposure $>20$ joint-years (table 4), further supporting the findings in table 3.

Current and former marijuana and tobacco smoking was further explored in those with $>20$ joint-years and $>20$ pack-years exposures, respectively. In marijuana smokers, current and former smoking status was significantly associated with declines in $\mathrm{FEV}_{1}$ compared to never-smokers; by $30.9 \mathrm{~mL} \cdot$ year $^{-1}$ (absolute decline $42.4 \mathrm{~mL} \cdot \mathrm{year}^{-1}$ ) for current smokers and $27.1 \mathrm{~mL} \cdot \mathrm{year}^{-1}$ (absolute decline $38.6 \mathrm{~mL} \cdot \mathrm{year}^{-1}$ ) for former smokers (table 3; figure 3a). Similarly, in tobacco smokers, the current and former tobacco status was significantly associated with declines in $\mathrm{FEV}_{1}$ compared to never-smokers; by $40.3 \mathrm{~mL} \cdot \mathrm{year}^{-1}$ (absolute decline $50.1 \mathrm{~mL} \cdot \mathrm{year}^{-1}$ ) for current tobacco smokers and $8.4 \mathrm{~mL} \cdot \mathrm{year}^{-1}$ (absolute decline $18.2 \mathrm{~mL} \cdot \mathrm{year}^{-1}$ ) for former tobacco smokers (table 3; figure $3 \mathrm{~b}$ ).

\section{Discussion}

To our knowledge, this is the first longitudinal study of marijuana smoking in older individuals in a general population whose median age was 65 years. The results from previous longitudinal studies [11, 12, $14,15,17]$ in younger people have shown that marijuana smoking produced marginal or no effects on lung function. The results of the present study address a major gap in marijuana research [30] by
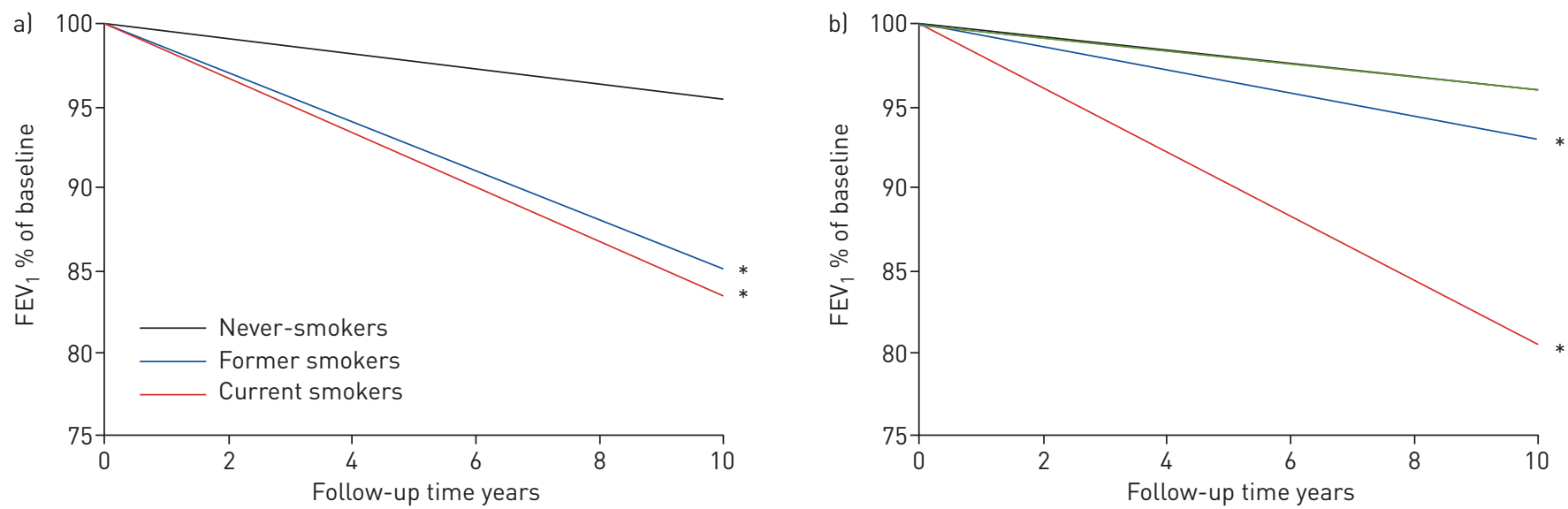

FIGURE 3 Decline in forced expiratory volume in $1 \mathrm{~s}\left(\mathrm{FEV}_{1}\right)$ over time for current and former smokers in a) marijuana smokers with cumulative exposure to $>20$ joint-years, controlled for pack-years; b) tobacco smokers with cumulative exposure to $>20$ pack-years, controlled for joint-years. Other covariates controlled for: sex, body mass index, baseline age, baseline $\mathrm{FEV}_{1}$, follow-up time and presence or absence of chronic obstructive

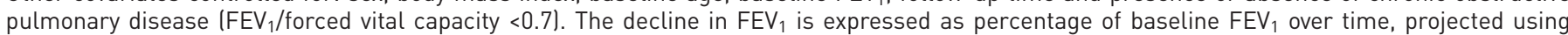
the $\beta$-coefficients from the mixed-effect models (data in table 3 ) and right-truncated at 10 years of follow-up. *: significantly different from never-smokers. 
demonstrating that marijuana smoking amplifies the harmful effects of tobacco smoking on risk of COPD and $\mathrm{FEV}_{1}$ decline over time.

Meta-analyses and systematic reviews $[5,31,32]$ generally agree that marijuana smoking causes respiratory symptoms and increases the risk of chronic bronchitis among long-term cannabis smokers. Yet, several cross-sectional studies and five longitudinal studies [12, 14-17] that have previously evaluated the effects of marijuana smoking on lung function have yielded mixed results. Three [7-9] out of the 11 studies $[6-13,17,33,34]$ found an association with low $\mathrm{FEV}_{1} / \mathrm{FVC}$ ratio; three studies $[9,12,13]$ reported an increase in $\mathrm{FVC}$, casting doubt on airflow limitation as defined by $\mathrm{FEV}_{1} / \mathrm{FVC}$ ratio; and four studies $[6,11,12,35]$ demonstrated a significant decrease in specific airway conductance, indicating large-airway obstruction. Explanations for these conflicting results are unclear, but could be attributed to 1) heterogeneity of study designs such as convenience sampling of volunteers $[6,11,13,35]$ versus community-based sampling $[10,12,17,33]$ versus birth cohorts [7, 12]; 2) small sample sizes and short follow-up times [10, 35]; 3) wide age ranges with many predominantly recruiting adults aged $<40$ years [7, 8, 34]; and 4) uncertainty in the accuracy of self-reports of marijuana use.

Two previous longitudinal studies, one a birth-cohort study [15] and a more recent population-based study [14] involving younger adults ( $<40$ years) found that the association between cumulative marijuana exposure and $\mathrm{FEV}_{1}$ was non-linear, with a positive relationship among those who had minor exposures to marijuana and a negative relationship among those who had higher joint-years of exposure. In the present study, we did not find a clear trend between marijuana exposure and lung function, which may be due to the small number of subjects who smoked marijuana exclusively and the challenges in accurately quantifying their exposure history; however, we did find a significant association between cumulative joint-years and presence of $\mathrm{COPD}\left(\mathrm{FEV}_{1} / \mathrm{FVC}<0.7\right)$, suggesting that marijuana on its own or in conjunction with tobacco smoking contributes to increased risk of COPD.

In addition, we observed an accelerated $\mathrm{FEV}_{1}$ decline in heavy marijuana smokers who had a cumulative exposure $>20$ joint-years. However, these data should be interpreted cautiously, as the absolute numbers of "pure" marijuana smokers were small (representing just 3\% of the entire cohort) and we could not validate their self-report with objective measurements of exposure. Moreover, there were significant differences in the age distribution of marijuana smokers versus all other groups. Although we used well-accepted statistical methods to adjust for these differences, residual confounding effects of age and other factors could have distorted the overall findings.

The importance of the age effect on rate of $\mathrm{FEV}_{1}$ decline deserves some emphasis. In clinical practice, the risk of COPD increases exponentially with increasing age, especially among those aged $\geqslant 40$ years [27]. Thus, the effects of marijuana smoke with or without concomitant tobacco exposure on the rate of lung function decline are likely best evaluated in middle-aged or older adults. Most of the previous studies on this topic have studied largely younger adults in contrast to our cohort of older individuals which had a median age of 65 years. This may in part explain some of the discrepancies in results between the present study and those previously reported $[11,12,14,15,17]$.

The observations for former and current smokers in this study are consistent with previous data showing that smoking cessation of tobacco reduces the rate of $\mathrm{FEV}_{1}$ decline to normal or near-normal levels [36, 37]. Our findings extend these observations by raising the possibility that elimination of exposure to marijuana cigarettes may also have a modifying effect on $\mathrm{FEV}_{1}$ decline, but perhaps not to the same extent as tobacco smoking cessation. However, as noted previously, measurement of marijuana exposure is not standardised; thus, some active marijuana smokers may have been misclassified as ex-smokers. Future studies will be required to elucidate the exact mechanisms behind this observation.

\section{Strength and limitations}

The strengths of this study included a large sample size of $>1200$ individuals, who were chosen from a larger cross-sectional study of $>5200$ individuals, who had been randomly selected from a general population; a large number of individuals who were in their fifth and sixth decades of life, and thus were at a peak susceptibility for the development of COPD; and a detailed exposure history of marijuana and tobacco smoke use and careful ascertainment of post-bronchodilator lung function measurements over time.

There were some limitations to the study. For example, not all participants from the cross-sectional cohort were included in the subsequent longitudinal component of the study, which may limit the generalisability of the longitudinal findings to the general population. It was reassuring that the baseline characteristics of the cross-sectional cohort and the derived longitudinal cohort were similar and the results from both cross-sectional and longitudinal analyses were concordant, suggesting that the CanCOLD sampling was unbiased. Another limitation was that the CanCOLD cohort was not specifically designed for the current analysis and the enrichment of the longitudinal cohort with COPD subjects could have caused a potential 
bias towards a more rapid decline in $\mathrm{FEV}_{1}$ in the smokers. However, because COPD subjects were present in all smoking subgroups as well as the reference group, it is unlikely that this feature of the study design would have significantly impacted the overall findings. Other limitations included 1) residual confounding by tobacco smoke: although we adjusted statistically for the history of tobacco smoking, this may not have fully captured the effects of life-time exposure of tobacco given that most "hard-core" marijuana smokers have also smoked tobacco cigarettes in the past $[9,13,14]$;2) challenges in accurately measuring exposure to marijuana smoke; and 3) the small numbers of heavy marijuana-only smokers, and a much larger group of individuals who smoked both marijuana and tobacco, which is a common smoking behaviour in North American and European communities [38, 39].

In summary, the present study indicates that individuals who smoke or smoked both marijuana and tobacco experienced a faster decline in lung function compared with tobacco-only smokers. The harmful effects of marijuana smoke on the rate of $\mathrm{FEV}_{1}$ decline appear to occur with exposures that are $>20$ joint-years. Although our study did not have sufficient power to evaluate the effects of marijuana smoke alone on lung function decline, these data raise concerns that marijuana exposure (especially in exand current tobacco smokers) may increase the risk of COPD and accelerate its progression for those who already have the disease. In view of marijuana smoking becoming more mainstream with increasing prevalence, following the legalisation of recreational marijuana in many countries and jurisdictions, there is a pressing need for larger longitudinal cohort studies that are specifically powered to evaluate the effects of marijuana alone on the risk of COPD and on lung function decline in those with established disease.

Acknowledgements: The authors would like to thank all who participated in the study and individuals in the CanCOLD Collaborative Research Group.

Members of the CanCOLD Collaborative Research Group not listed as authors: Jonathon Samet (the Keck School of Medicine of USC, Los Angeles, CA, USA); Milo Puhan (John Hopkins School of Public Health, Baltimore, MD, USA); Qutayba Hamid, Carole Baglole, Palmina Mancino, Yvan Fortier, Zhi Song (McGill University, Montreal, QC, Canada); Joe Comeau, Harvey Coxson, Miranda Kirby, Jonathon Leipsic, Cameron Hague, Christine Lo, Sarah Cheng, Elena Un, Cindy Fung, Nancy Haynes, Wen Tian Wang, Jijie Xu, Faize Faroon (University of British Columbia James Hogg Research Center, Vancouver, BC, Canada); Mohsen Sadatsafavi (University of British Columbia, Vancouver, BC); Andrea Gershon, Jane Duke (University of Toronto, Toronto, ON, Canada); Pei-Zhi Li, Denis Jensen (McGill University, Montreal, QC, Canada); Curtis Dumonceaux (University of Calgary, Calgary, AB, Canada); Scott Fulton (University of Halifax, Halifax, NS, Canada); Kathy Vandemheen (University of Ottawa, Ottawa, ON, Canada); Matthew McNeil, Kate Whelan (Queen's University, Kingston, ON, Canada); Cynthia Brouillard (University of Laval, Quebec City, QC, Canada); Ron Clemens, Janet Baran (University of Saskatchewan, Saskatoon, SK, Canada).

Author contributions: W.C. Tan, J. Bourbeau and D.D. Sin contributed to the design and implementation of the study, the collection of data, the analysis and interpretation of the data and the writing of the manuscript. S.D. Aaron, K.R. Chapman, B.L. Walker, J.M. FitzGerald, P. Hernandez, F. Maltais, D.D. Marciniuk, D. O’Donnell, J.C. Hogg and J. Road contributed to the collection and interpretation of data, and the revision of the manuscript. T. Yau, G. Zhou, L. Zheng, T. To and A. Benedetti contributed to the analysis and interpretation of the data and revision of manuscript. W.C. Tan and J. Bourbeau had full access to all the data in this study, and had final responsibility for the decision to submit this manuscript for publication. All authors approved the final version of the manuscript.

Conflict of interest: W.C. Tan reports grants from Canadian Institute of Heath Research (CIHR/Rx\&D Collaborative Research Program Operating Grants-93326) with industry partners AstraZeneca Canada Ltd, Boehringer Ingelheim Canada Ltd, GlaxoSmithKline Canada Ltd, Merck, Novartis Pharma Canada Inc., Nycomed Canada Inc., Pfizer Canada Ltd, during the conduct of the study. J. Bourbeau reports grants from Canadian Institute of Heath Research (CIHR/ Rx\&D Collaborative Research Program Operating Grants-93326) with industry partners AstraZeneca Canada Ltd, Boehringer Ingelheim Canada Ltd, GlaxoSmithKline Canada Ltd, Merck, Novartis Pharma Canada Inc., Nycomed Canada Inc., Pfizer Canada Ltd, during the conduct of the study. S.D. Aaron has nothing to disclose. J.C. Hogg has nothing to disclose. F. Maltais has nothing to disclose. P. Hernandez reports grants from Canadian Institute Health Research, during the conduct of the study; grants and personal fees from AstraZeneca, Boehringer Ingelheim, GlaxoSmithKline, Novartis and Takeda, personal fees from Merck, Grifols, Pfizer and Almirall, grants from CSL Behring, outside the submitted work. D.D. Marciniuk has nothing to disclose. K.R. Chapman reports grants from Novartis, Almirall, Boehringer Ingelheim, Forest, GSK, AstraZeneca, Amgen, Roche, CSL Behring, Grifols, Genentech and Kamada, during the conduct of the study; UHN administered personal support from CIHR (GSK Research Chair in Respiratory Health Care Delivery), outside the submitted work. T. To has nothing to disclose. J.M. FitzGerald has nothing to disclose. B.L. Walker reports grants from Canadian Institute of Health Research, AstraZeneca Canada Ltd, Boehringer Ingelheim Canada, GlaxoSmithKline Canada and Novartis, during the conduct of the study; grants from Respiratory Health Strategic Clinical Network Alberta, personal fees from AstraZeneca, GlaxoSmithKline and Novartis, outside the submitted work. J. Road has nothing to disclose. L. Zheng has nothing to disclose. G. Zhou has nothing to disclose. T. Yau has nothing to disclose. A. Benedetti has nothing to disclose. D. O'Donnell has nothing to disclose. D.D. Sin reports grants from Merck, personal fees for advisory board work from Sanofi-Aventis and Regeneron, grants and personal fees from Boehringer Ingelheim, grants and personal fees for lectures and advisory board work from AstraZeneca, personal fees for lectures and advisory board work from Novartis, outside the submitted work.

Support statement: The Canadian Cohort Obstructive Lung Disease (CanCOLD) study is currently funded by the Canadian Respiratory Research Network (CRRN); industry partners: AstraZeneca Canada Ltd; Boehringer Ingelheim Canada Ltd; GlaxoSmithKline Canada Ltd; Novartis. Researchers at RI-MUHC Montreal and UBC Centre for Heart 
Lung Innovation, Vancouver lead the project. Previous funding partners were the CIHR (CIHR/Rx\&D Collaborative Research Program Operating Grants-93326); the Respiratory Health Network of the FRSQ; industry partners: Almirall; Merck Nycomed; Pfizer Canada Ltd; and Theratechnologies. The funding sponsors had no role in the study design; in the collection, analysis, and interpretation of data, in the writing of this manuscript or in the decision to submit this manuscript for publication. The funders had no role in the study design, data collection and analysis, or preparation of the manuscript. Funding information for this article has been deposited with the Crossref Funder Registry.

\section{References}

1 World Health Organization. The Health and Social Effects of Nonmedical Cannabis Use. Geneva, World Health Organization, 2016. www.who.int/substance_abuse/publications/cannabis/en/ 2016

2 Lloyd SL, Striley CW. Marijuana use among adults 50 years or older in the 21st century. Gerontol Geriatr Med 2018; 4: 2333721418781668 .

3 Centers for Disease Control and Prevention. 2017. Health Effects of Cigarette Smoking. www.cdc.gov/tobacco/ data_statistics/fact_sheets/health_effects/effects_cig_smoking/index.htm Date last updated: 17 January 2018.

4 Douglas IS, Albertson TE, Folan P, et al. Implications of marijuana decriminalization on the practice of pulmonary, critical care, and sleep medicine. a report of the American Thoracic Society Marijuana Workgroup. Ann Am Thorac Soc 2015; 12: 1700-1710.

5 Ghasemiesfe M, Ravi D, Vali M, et al. Marijuana use, respiratory symptoms, and pulmonary function: a systematic review and meta-analysis. Ann Intern Med 2018; 169: 106-115.

6 Aldington S, Williams M, Nowitz M, et al. Effects of cannabis on pulmonary structure, function and symptoms. Thorax 2007; 62: 1058-1063.

7 Taylor DR, Poulton R, Moffitt TE, et al. The respiratory effects of cannabis dependence in young adults. Addiction 2000; 95: 1669-1677.

8 Bloom JW, Kaltenborn WT, Paoletti P, et al. Respiratory effects of non-tobacco cigarettes. Br Med J (Clin Res Ed) 1987; 295: 1516-1518.

9 Kempker JA, Honig EG, Martin GS. The effects of marijuana exposure on expiratory airflow. A study of adults who participated in the U.S. National Health and Nutrition Examination Study. Ann Am Thorac Soc 2015; 12: $135-141$.

10 Tan WC, Lo C, Jong A, et al. Marijuana and chronic obstructive lung disease: a population-based study. CMAJ 2009; 180: 814-820.

11 Tashkin DP, Coulson AH, Clark VA, et al. Respiratory symptoms and lung function in habitual heavy smokers of marijuana alone, smokers of marijuana and tobacco, smokers of tobacco alone, and nonsmokers. Am Rev Respir Dis 1987; 135: 209-216.

12 Hancox RJ, Poulton R, Ely M, et al. Effects of cannabis on lung function: a population-based cohort study. Eur Respir J 2010; 35: 42-47.

13 Morris MA, Jacobson SR, Kinney GL, et al. Marijuana use associations with pulmonary symptoms and function in tobacco smokers enrolled in the Subpopulations and Intermediate Outcome Measures in COPD Study (SPIROMICS). Chronic Obstr Pulm Dis 2018; 5: 46-56.

14 Pletcher MJ, Vittinghoff E, Kalhan R, et al. Association between marijuana exposure and pulmonary function over 20 years. JAMA 2012; 307: 173-181.

15 Taylor DR, Fergusson DM, Milne BJ, et al. A longitudinal study of the effects of tobacco and cannabis exposure on lung function in young adults. Addiction 2002; 97: 1055-1061.

16 Tashkin DP, Simmons MS, Sherrill DL, et al. Heavy habitual marijuana smoking does not cause an accelerated decline in $\mathrm{FEV}_{1}$ with age. Am J Respir Crit Care Med 1997; 155: 141-148.

17 Sherrill DL, Krzyzanowski M, Bloom JW, et al. Respiratory effects of non-tobacco cigarettes: a longitudinal study in general population. Int J Epidemiol 1991; 20: 132-137.

18 Tan WC, Bourbeau J, Hernandez P, et al. Exacerbation-like respiratory symptoms in individuals without chronic obstructive pulmonary disease: results from a population-based study. Thorax 2014; 69: 709-717.

19 Bourbeau J, Tan WC, Benedetti A, et al. Canadian Cohort Obstructive Lung Disease (CanCOLD): fulfilling the need for longitudinal observational studies in COPD. COPD 2014; 11: 125-132.

20 Tan WC, Bourbeau J, FitzGerald JM, et al. Can age and sex explain the variation in COPD rates across large urban cities? A population study in Canada. Int J Tuberc Lung Dis 2011; 15: 1691-1698.

21 Labonté LE, Tan WC, Li PZ, et al. Undiagnosed chronic obstructive pulmonary disease contributes to the burden of health care use. Data from the CanCOLD study. Am J Respir Crit Care Med 2016; 194: 285-298.

22 Tan WC, Hague CJ, Leipsic J, et al. Findings on thoracic computed tomography scans and respiratory outcomes in persons with and without chronic obstructive pulmonary disease: a population-based cohort study. PLoS One 2016; 11: e0166745.

23 Buist AS, McBurnie MA, Vollmer WM, et al. International variation in the prevalence of COPD (the BOLD Study): a population-based prevalence study. Lancet 2007; 370: 741-750.

24 Tan WC, Sin DD, Bourbeau J, et al. Characteristics of COPD in never-smokers and ever-smokers in the general population: results from the CanCOLD study. Thorax 2015; 70: 822-829.

25 Tan WC, Bourbeau J, O'Donnell D, et al. Quality assurance of spirometry in a population-based study predictors of good outcome in spirometry testing. COPD 2014; 11: 143-151.

26 Standardization of Spirometry, 1994 Update. American Thoracic Society. Am J Respir Crit Care Med 1995; 152: $1107-1136$

27 Global Initiative for Chronic Obstructive Lung Disease. Global Strategy for the Diagnosis, Management, and Prevention of Chronic Obstructive Pulmonary Disease: Revised 2011. https:/goldcopd.org/archived-reports/

28 Gibbons RD, Hedeker D, DuToit S. Advances in analysis of longitudinal data. Annu Rev Clin Psychol 2010; 6 : 79-107.

29 Burnham KP, Anderson DR. Multimodel inference understanding AIC and BIC in model selection. Sociol Methods Res 2004; 33: 261-304.

30 Tashkin DP. Increasing cannabis use: what we still need to know about its effects on the lung. Respirology 2014; 19: 619-620. 
31 Gates P, Jaffe A, Copeland J. Cannabis smoking and respiratory health: consideration of the literature. Respirology 2014; 19: 655-662.

32 Tashkin DP. Marijuana and lung disease. Chest 2018; 154: 653-663.

33 Moore BA, Augustson EM, Moser RP, et al. Respiratory effects of marijuana and tobacco use in a U.S. sample. J Gen Intern Med 2005; 20: 33-37.

34 Macleod J, Robertson R, Copeland L, et al. Cannabis, tobacco smoking, and lung function: a cross-sectional observational study in a general practice population. Br J Gen Pract 2015; 65: e89-e95.

35 Tashkin DP, Calvarese BM, Simmons MS, et al. Respiratory status of seventy-four habitual marijuana smokers. Chest 1980; 78: 699-706.

36 Kohansal R, Martinez-Camblor P, Agustí A, et al. The natural history of chronic airflow obstruction revisited: an analysis of the Framingham offspring cohort. Am J Respir Crit Care Med 2009; 180: 3-10.

37 Scanlon PD, Connett JE, Waller LA, et al. Smoking cessation and lung function in mild-to-moderate chronic obstructive pulmonary disease. The Lung Health Study. Am J Respir Crit Care Med 2000; 161: 381-390

38 Agrawal A, Budney AJ, Lynskey MT. The co-occurring use and misuse of cannabis and tobacco: a review. Addiction 2012; 107: 1221-1233.

39 Hernández-Serrano O, Gras ME, Font-Mayolas S. Concurrent and simultaneous use of cannabis and tobacco and its relationship with academic achievement amongst university students. Behav Sci 2018; 8: E31. 